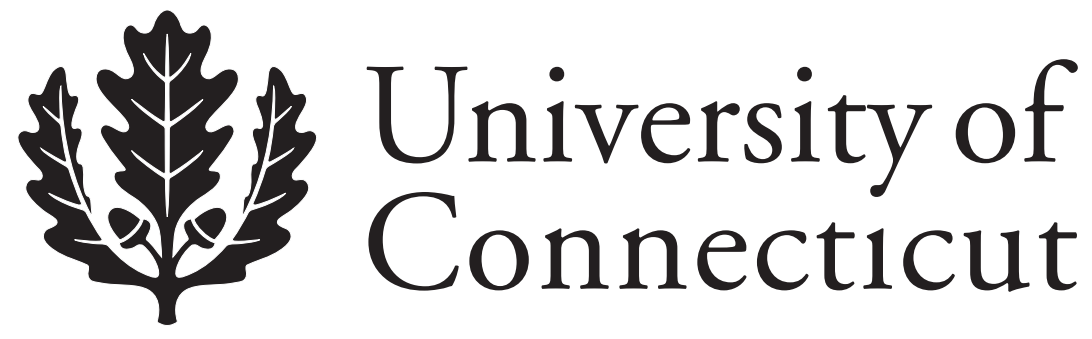

Department of Economics Working Paper Series

\title{
Public Goods, Taxes, and Takings
}

Thomas Miceli

University of Connecticut

Working Paper 2007-02

February 2007

341 Mansfield Road, Unit 1063

Storrs, CT 06269-1063

Phone: (860) 486-3022

Fax: (860) 486-4463

http://www.econ.uconn.edu/

This working paper is indexed on RePEc, http://repec.org/ 


\begin{abstract}
Blume, Rubinfeld, and Shapiro (1984) first showed that compensation for takings can lead to a moral hazard problem that results in overinvestment in land suitable for public use. To the contrary, this paper shows that the compensation rule is irrelevant regarding the level of investment landowners make in their property, as well as the amount of land they authorize the government to acquire, both of which will be efficient. Intuitively, landowners recognize the equivalence of taxes and takings in budgetary terms, causing the distortionary effects of compensation and property taxation to cancel each other out through the balanced budget condition.
\end{abstract}

Journal of Economic Literature Classification: H41, K11, R52

Keywords: Compensation for takings, eminent domain, moral hazard, public goods 


\section{Public Goods, Taxes, and Takings}

\section{Introduction}

Since the seminal paper by Blume, Rubinfeld, and Shapiro (1984), economic models of eminent domain have struggled to reconcile their "no-compensation result," which is a consequence of the moral hazard problem associated with compensation, with the constitutional requirement of "just compensation." A frequent argument in favor of compensation is the claim that the government will take too much land if it is not forced to pay for it. A government that acts in this way is sometimes said to have "fiscal illusion."

A noteworthy example of this approach to the compensation question is the paper by Fischel and Shapiro (1989), ${ }^{1}$ in which individuals, acting from behind a veil of ignorance, choose the compensation rule without knowing how many, or which, parcels will be taken for public use. In this setting, the authors show that, if the government is assumed to maximize the welfare of the majority of landowners (rather than overall welfare), then partial compensation is optimal, reflecting the trade-off between the tendency for landowners to overinvest under full compensation (moral hazard), and the risk of excessive government seizure of land under zero compensation (fiscal illusion).

A different tack in the search for an optimal compensation rule emerges from Richard Epstein's controversial assertion that taxes are themselves a form of taking in the sense that they, like takings, represent coercive transfers of resources to the government.

\footnotetext{
${ }^{1}$ Other papers in this vein include Miceli and Segerson (1994), Hermalin (1995), and Nosal (2001). Another argument for compensation is to provide insurance against takings risk to risk averse landowners See Blume and Rubinfeld (1984) and Kaplow (1986).
} 
Epstein acknowledges, however, that if the tax revenue is used to provide a public good, then the resulting benefits represent "in-kind" compensation of the taxpayer, thus satisfying the constitutional requirement (Epstein, 1985, p. 196). It follows, though, that any taxpayers who do not receive benefits in line with their tax payments are in some sense "undercompensated." Fischel (1995a, pp. 210-211) has observed that this undercompensation parallels that suffered by actual takings victims who receive market value compensation for their land (the legal definition of just compensation), which almost certainly falls short of the minimum amount owners would ask in a consensual sale (i.e., their true reservation prices).

The parallel between these two forms of undercompensation is further revealed by the public budget, which requires that any increase in compensation for the benefit of takings victims represents a cost that must be borne by taxpayers. This insight has led Fischel to conjecture that market value compensation emerged as the legal definition of just compensation because constitution writers, acting from behind a veil of ignorance, recognized their dual roles as taxpayers and potential takings victims, and therefore sought a way of "balancing the undercompensation of the market-based rule against the greater loss incurred by higher taxes and foregoing public works that full, consensual compensation would require" (Fischel, 1995a, p. 211). We will refer to this claim as the "Epstein-Fischel conjecture."

The purpose of this paper is to evaluate these competing approaches to the compensation question — namely, the moral hazard-fiscal illusion trade-off embodied by the BRS model, and the Epstein-Fischel conjecture—in a coherent framework that simultaneously examines the choice of how much land will taken for public use, and how 
much capital landowners will invest in their land, given the compensation rule. Since both decisions can be couched in constitutional-choice terms, we adopt the Fischel and Shapiro framework with some crucial changes. First, we assume that individuals differ both in their valuations of the public good, and in their reservation prices for their land. Second, we assume that these valuations are unobservable to the government. This rules out the use of benefit (or Lindahl) taxes for the public good, and also requires the use of an objective measure of compensation for takings (for example, fair market value or some fixed fraction thereof). Third, we assume that the government finances compensation with a property tax that is assessed on the market value of a given property, as opposed to a lump sum tax. While this would seem to introduce an additional source of inefficiency into the model (given that a proportional tax is distortionary while a lump sum tax is not), this turns out not to be the case. In fact, we show that under certain conditions, the property tax distortion exactly offsets the moral hazard effect of compensation, thereby producing a kind of irrelevance result regarding the compensation rule. Specifically, landowners make the efficient investment choice, and also allocate the efficient amount of land to public use (public choice considerations aside), regardless of the amount of compensation. These conclusions are in sharp contrast to the existing literature.

The remainder of the paper is organized as follows. Section 2 sets up the basic model. Section 3 examines the impact of the compensation rule on the investment choice of landowners. Section 4 then asks how the compensation rule affects the level of takings that landowners will authorize when acting from behind a veil of ignorance regarding which parcels will actually be taken. Finally, Section 5 concludes. 


\section{The Model}

The basic model follows that developed by Fischel and Shapiro (FS) (1989). Consider a government that will provide a pure public good like a park or highway requiring the assembly of land. In particular, suppose there are a total of $n$ parcels of land, $s<n$ of which will be taken at random for purposes of providing the public good. ${ }^{2}$ (For simplicity, we assume that land is the sole input.) Thus, the probability that any given parcel will be taken is given by $p=s / n$, while the probability that it will not be taken is $1-p=(n-s) / n$. Let the quantity of the public good be $G(s)$, where $G^{\prime}>0$. We assume that $G$ is a pure public good in the sense that, once it is provided, all residents consume the full quantity (including those whose land is taken), ${ }^{3}$ regardless of how much they contributed to the cost. Let $v_{i}(G)$ be individual $i$ 's valuation function of $G$, where $v_{i}{ }^{\prime}>0$, $v_{i}^{\prime \prime}<0$. To conserve on notation, we will henceforth write $v_{i}(s)$ instead of $v_{i}(G(s))$.

We assume that the $v_{i}$ 's are unobservable to the government, so $i$ 's contribution to the cost of $G$ cannot depend on his or her valuation. This rules out of any form of benefit tax. We also ignore demand-revealing tax schemes as impractical. Instead, we assume that the government imposes a uniform property tax on the assessed value of each parcel. We also assume (without loss of generality) that all parcels have equal assessed values, given by $A$. Thus, the tax payment of each individual whose land is not taken is $t A$, where $t$ is the tax rate to be determined below. This method of assessing taxes represents a critical distinction from FS, who assumed that taxes were lump sum rather than depending on the actual assessed value of the property. The method of taxation here is

\footnotetext{
${ }^{2}$ The fact that the parcels are taken randomly suggests that they are scattered throughout the jurisdiction, which seems inconsistent with the idea of assembly. The randomness assumption is valid, however, if the location of the project is random and is made public, along with all parcels to be taken, at a single point in time.

${ }^{3}$ This assumption is inessential and is consistent with Fischel and Shapiro (1989).
} 
more reflective of actual practice, but also has important implications to be discussed below.

In contrast to the assessed value, we assume that the true (subjective) values of the parcels are individual-specific and unobserved by the government. Specifically, let $V_{i}$ be the value owner $i$ attaches to his land. This represents the amount that he would sell it for in a consensual (market) transaction, where we assume that $V_{i} \geq A$ for all $i$. The distinction between the fair market value of a piece of land and its subjective value to the owner is crucial because it is what makes eminent domain a non-consensual purchase. This distinction, however, is not often made in the economic literature on takings. ${ }^{4}$

Finally, let $C(A)$ be the amount of compensation paid by the government to each landowner whose land is taken. We do not write $C$ as a function of $V$ because, as noted, the owner's true valuation is unobservable to the government and hence cannot form a basis for compensation. The only other restrictions we place on $C$ are that it is nonnegative $(C \geq 0)$ and non-decreasing in $A(C \geq 0)$. An important special case is $C(A)=A$, which reflects the traditional legal definition of just compensation as being equal to the fair market value of the parcel (which we assume is the same as its assessed value).

A crucial element of the model is the public budget, which provides the link between the tax assessed on untaken parcels and the compensation paid to owners of taken parcels. Assuming that the public good, $G$, is the only public expenditure, and the land input is the only cost of $G$, we can write the balanced budget condition as

$$
t(n-s) A=s C(A),
$$

where the left-hand side is total revenue and the right-hand side is total cost. Using the definition of $p$ above, we can rewrite this condition as

\footnotetext{
${ }^{4}$ Exceptions include Knetsch and Borcherding (1979) and Fischel (1995b)
} 


$$
t=\frac{p}{1-p} \frac{C(A)}{A}
$$

It follows that if $C(A)=A$ (fair market value compensation), $t=p /(1-p)$, while, at the other extreme, if $C(A)=0$ (zero compensation), $t=0$.

Given this specification, we can write the realized utility of an individual whose land is not taken as

$$
U_{i}^{N}=V_{i}-t A+v_{i}(s)
$$

Likewise, the realized utility of an individual whose land is taken is

$$
U_{i}^{T}=C(A)+v_{i}(s)
$$

Weighting these expressions by the appropriate probabilities and summing yields expected utility:

$$
\begin{aligned}
E U_{i} & =p U_{i}^{T}+(1-p) U_{i}^{N} \\
& =p C(A)+(1-p)\left(V_{i}-t A\right)+v_{i}(s) .
\end{aligned}
$$

Finally, note that the utility of all individuals in the absence of government action is $U_{i}^{0}=$ $V_{i}$. That is, there is no risk of a taking, no tax liability, but also no public good.

\section{Landowner Investment and Moral Hazard}

Since the original article by Blume, Rubinfeld, and Shapiro (BRS) (1984), the economic analysis of compensation for takings has focused on how the compensation rule affects landowner incentives to make irreversible capital investments in their property. In this setting, BRS derived the famous no-compensation result based on the moral hazard problem associated with full compensation.

We introduce landowner investment into the above model by letting the assessed and true valuations of landowner $i$ be given by $A\left(x_{i}\right)$ and $V_{i}\left(x_{i}\right)$, respectively, where $x_{i}$, is 
the dollar amount that $i$ invests in capital improvements. We assume that both $A$ and $V_{i}$ are increasing, concave functions of $x$. (Note that, while we continue to assume that the function $A(\cdot)$ is the same for all landowners, the realized assessed values of the properties will differ if landowners choose different $x_{i}$ 's.) In this case, expected utility in (5) becomes

$$
E U_{i}=p C\left(A\left(x_{i}\right)\right)+(1-p)\left[V_{i}\left(x_{i}\right)-t A\left(x_{i}\right)\right]+v_{i}(s)-x_{i},
$$

where all other variables are defined as above.

The socially optimal $x_{i}$ (given $p$ ), maximizes the expected net value of the investment $(1-p) V_{i}\left(x_{i}\right)-x_{i}$, yielding the first-order condition

$$
(1-p) V_{i}^{\prime}\left(x_{i}\right)=1
$$

Denote the resulting level of investment $x_{i}{ }^{*}$, which will in general differ across landowners due to differences in their true valuations of land.

Landowner $i$ will in fact choose $x_{i}$ to maximize (6), taking as given the tax rate and compensation rule. This yields the first-order condition

$$
\left[p C_{i}^{\prime}-(1-p) t\right] A^{\prime}\left(x_{i}\right)+(1-p) V_{i}^{\prime}\left(x_{i}\right)=1 \text {. }
$$

Note that this differs from (7) by the first term on the left-hand side. The question is, under what conditions will this term vanish, resulting in the efficient level of investment. Note first that in the BRS model, this term consists only of the $C^{\prime}$ term, which yields the result that $C^{\prime}$ must equal zero for efficiency. ${ }^{5}$ The same result emerges in the FS model since they treat landowner $i$ 's tax payment as lump sum rather than as being assessed on $A\left(x_{i}\right)$.

\footnotetext{
${ }^{5}$ The no-compensation result therefore really says that compensation must be lump sum (that is, $C^{\prime}=0$ ), a special case of which is $C=0$.
} 
In the current model, in contrast, the efficiency of $x_{i}$ depends in part on how it affects the equilibrium tax rate. Note first that this rate differs from the calculation in (2) owing to the presence of the landowners' investments, which may cause the assessed values to vary. To conserve on notation, we define $A_{i} \equiv A\left(x_{i}\right)$ and $C_{i} \equiv C\left(A\left(x_{i}\right)\right)$. Also, let $S$ be the set of properties taken, and let $N$ be the set of properties not taken. We continue to assume that the government takes $s$ properties at random, which in the current setting means that the taking decision is independent of the owner's choice of $x_{i}$. (For example, the government, although it observes the $x_{i}$ 's, does not systematically prefer those parcels with less improvements. Rather, those parcels taken are purely dependent on the demands of the public project, which we assume do not depend on the existing state of the properties.) ${ }^{6}$ This implies that the properties in both $S$ and $N$ are random samples of the population of all properties.

Given these assumptions, we can write the new balanced budget condition as

$$
t \sum_{i \in N} A_{i}=\sum_{i \in S} C_{i}
$$

Now define $\bar{A}$ to be the average assessed value in the population of taxpayers after landowners have made their investments, and let $\bar{C}$ be the corresponding average compensation amounts for owners whose land is taken. That is,

$$
\bar{A} \equiv \frac{1}{n-s} \sum_{i \in N} A_{i}
$$

and

$$
\bar{C} \equiv \frac{1}{s} \sum_{i \in S} C_{i}
$$

\footnotetext{
${ }^{6}$ One might argue that the government would prefer parcels with less development because this would involve less cost of clearing off the improvements. We assume that other factors, such as location and assembly considerations, dominate.
} 
It follows that (9) can be written as

$$
t(n-s) \bar{A}=s \bar{C}
$$

Obviously, (1) is a special case of (10) when all landowners make the same investment in their land. Solving (10) for $t$ and using the definitions of $p$ and $1-p$ yields

$$
t=\frac{p \bar{C}}{(1-p) \bar{A}}
$$

which corresponds to (2).

Now use (11) to substitute for $t$ in the first term of (8). It thus becomes

$$
p\left[C_{i}{ }^{\prime}-\frac{\bar{C}}{\bar{A}}\right] A^{\prime}\left(x_{i}\right) .
$$

Generally, this expression will not be zero, but suppose, following FS, that the compensation rule takes the form $C_{i}=\alpha A_{i}$ for all $i$, where $\alpha$ is a non-negative constant. ${ }^{7}$ That is, compensation is proportional to the assessed value of the property. Obviously, this rule implies that $C_{i}{ }^{\prime}=\bar{C} / \bar{A}=\alpha$ for all $i$, in which case (12) is zero. Thus, the extra term in (8) vanishes. This proves the following result.

Proposition 1: Assume that the compensation rule takes the form $C_{i}=\alpha A_{i}$ and taxes are uniformly assessed on the market value of individual properties. Then landowners will make the socially efficient investment choices regardless of the value of $\alpha$.

It follows that awarding market value compensation for takings $(\alpha=1)$, or zero compensation $(\alpha=0)$, will both induce efficient investment. It is important to emphasize

\footnotetext{
${ }^{7}$ Note that $\alpha$ is not restricted to be less than or equal to one. For example, Epstein (1985, p.174) describes the New Hampshire Mill Act, which allowed would-be mill builders to flood upstream property without first obtaining the owners' consent, provided that the mill builders paid compensation equal to $150 \%$ of the owner's market value (i.e., $\alpha=1.5$ ).
} 
that this result is not a consequence of any particular assumption about the objective function of the government. Rather, it reflects the trade-off arising from the fact that landowners are simultaneously taxpayers and potential victims of a taking and thus automatically internalize the marginal cost of investing in their land through the public budget constraint. ${ }^{8}$ As a result, the moral hazard problem vanishes, and with it, the trade-off between moral hazard and fiscal illusion. Compensation can therefore be determined solely for the purpose of preventing excessive takings, assigning takings risk optimally, or any other purpose.

Finally, consider the role of the property tax in deriving this conclusion. Note in particular that when (12) equals zero, the property tax and compensation distortions exactly offset with respect to the landowner's choice of $x$. The reason that this did not occur in FS is that they modeled the tax as lump sum, and hence, non-distortionary. ${ }^{9}$ Thus, only the compensation distortion (the $C^{\prime}$ term) remained. Here, in contrast, the tax, like the compensation rule, is proportional to the market value of the land, thus leading to offsetting distortions, which, by the balanced budget condition, must be exactly equal. ${ }^{10}$

\section{The Choice of Public Spending}

\footnotetext{
${ }^{8}$ Nosal's (2001) model contains the same trade-off, but in contrast to the current model, he constrains the compensation rule to be equal to the average market value of all landowners' properties, rather than depending on the actual value of the properties that are taken. Thus, his main conclusion, which is not inconsistent with that obtained here, is that market value compensation is efficient in equilibrium. ${ }^{9}$ Specifically, the individual tax payments depended on the equilibrium level of investment by all landowners, rather than on the amount each owner invested in his or her own property, as is assumed here. ${ }^{10}$ Hamilton (1975) derived a similar result in a very different context. In particular, he showed that in the Tiebout model of local public good provision, property taxes are not distortionary if communities are homogeneous in terms of taxable property. The reason is that, in a homogeneous community, the public budget transforms the property tax into a benefit tax for public goods. As a result, no free riding is possible, and consequently, landowners' choices of housing are not distorted by the tax.
} 
To this point, we have treated the level of the public good as fixed in order to focus on the landowner's investment choice. In this section, we consider the choice of $s$, assuming that landowners make this decision before the specific parcels to be taken are known. While this assumption may or may not be realistic, ${ }^{11}$ it provides a heuristic device for evaluating the Epstein-Fischel conjecture.

Given that landowners choose $s$ from behind a veil of ignorance, they are all in the same initial position and will therefore choose their desired level of $s$ to maximize $(5),{ }^{12}$ taking the compensation rule as given. (They will, however, recognize the dependence of $p$ and $t$ on $s$.) Thus, taking the derivative of (5) with respect to $s$ and setting it equal to zero yields ${ }^{13}$

$$
\left[v_{i}^{\prime}-(1-p) t^{\prime} A\right]=p^{\prime}\left[V_{i}-t A-C(A)\right] .
$$

Note that the left-hand side represents individual $i$ 's marginal net benefit from the public good. If there were no risk of taking, this term would be set equal to zero to determine individual $i$ 's demand for $s$. Since individuals differ in their marginal valuations but all pay the same taxes (given equal $A$ 's), this term will vary across landowners. Thus, the equilibrium $s$ would have to be determined by majority vote (or some other method for aggregating preferences), which may or may not result in the efficient level of $s$ (Atkinson and Stiglitz, 1980, pp. 507-509).

In terms of individual valuations, the resulting equilibrium could result in too much or too little $s$ from $i$ 's perspective. In the case where it is too much (i.e., where

\footnotetext{
${ }^{11}$ See the discussion by Fischel (1995a, pp. 204-205).

${ }^{12}$ In contrast, a majoritarian government would choose $s$ to maximize the utility of landowners whose land is not taken, given by (3). This is the assumption FS make to derive their partial compensation rule. As we showed in the previous section, however, when the moral hazard problem goes away, there is no longer a trade-off between moral hazard and fiscal illusion.

${ }^{13}$ In this section, we will treat $x$ as fixed and suppress it notationally.
} 
$\left.v_{i}{ }^{\prime}<(1-p) t^{\prime} A\right), i$ is overpaying at the margin, which corresponds to Epstein's case where the taxpayer receives insufficient in-kind compensation for his coercive tax payment. Conversely, in the case where $s$ is too small (i.e., $\left.v_{i}^{\prime}>(1-p) t^{\prime} A\right), i$ underpays and thus, according to Epstein's logic, receives too much compensation. (Individual $i$ is therefore a free rider in this case.)

Now consider the right-hand side of (13), which represents the impact of the taking risk on $i$ 's demand for $s$. Assuming that $V_{i}-t A-C(A)>0$, this term represents the expected undercompensation from a taking. ${ }^{14}$ Since $p^{\prime}>0$, the right-hand side of (13) is the expected marginal cost to landowner $i$ of authorizing the taking of one more parcel in the form of an increased risk that one's own property will be taken and insufficient compensation will be paid. The taking risk therefore reduces the demand for the public good, all else equal.

The fact that the two sides of (13) are equal at the optimum illustrates the fact that landowners, acting from behind a veil of ignorance, will recognize the symmetry between taxes and takings, given their dual roles as taxpayers and potential victims of a taking. ${ }^{15}$ Note that the compensation rule is crucial here, since taxpayers would prefer it to be low in order to reduce their tax liability (i.e., it enters (13) through the $t^{\prime}$ term), while takings victims would prefer it to be high to prevent undercompensation.

Now recall the Epstein-Fischel conjecture, which says that individuals would choose market value compensation — that is, $C(A)=A$ (or $\alpha=1$ ) —as a way of balancing

\footnotetext{
${ }^{14}$ Note that owners whose land is taken are partly compensated by the fact that they do not have to pay property taxes. This is an artifact of the assumption that taxes are only assessed on those landowners whose land is not taken.

${ }^{15}$ Another way to say this is that the two sides of (13) illustrate the interaction of the free rider problem (left-hand side) and the holdout problem (right-hand side) in determining the allocation of land to public use. See Cohen (1991).
} 
these offsetting interests. While recognizing that this amount would likely undercompensate victims of a taking, landowners balance that concern against their desire to limit their liability as taxpayers. To evaluate this conjecture, we use the balanced budget condition in (1) and (2), and the fact that $p=s / n$, to rewrite (13) as

$$
v_{i}^{\prime}=\frac{V_{i}}{n}
$$

Note that, while this condition continues to reflect varying demands for $s$ across individuals, these demands are independent of the compensation rule. Instead, they reflect the individual's true marginal benefit, and expected marginal cost, of a taking. ${ }^{16}$ Thus, any inefficiency in the determination of $s$ will be solely due to public choice factors (i.e., problems of aggregating preferences), rather than the amount of compensation or the manner in which it is calculated. We summarize this conclusion as follows.

Proposition 2: Assume that taxes are uniformly assessed on the market value of individual properties and that landowners authorize the number of parcels to be taken from behind a veil of ignorance regarding which particular parcels will be taken. Then the number of parcels taken will be independent of the compensation rule.

Although this result invalidates the Epstein-Fischel conjecture in the literal sense that it does not yield a determinate value for $C$, it nevertheless confirms the basic insight from which it emerged—namely, that individuals, acting from behind a veil of ignorance, would have accounted for both sides of the budget ledger in determining the proper

\footnotetext{
${ }^{16}$ In particular, note that the right-hand side of (14) is the expected cost to $i$ of one more taking, which is equal to the opportunity cost of his or her parcel, $V_{i}$, times the probability that it will be the one taken $(1 / n)$.
} 
measure of just compensation for takings. Further, this basic idea provides the common thread linking the analysis in this and the preceding sections: namely, that the "equivalence" of taxes and takings as embodied in the public budget renders the compensation rule irrelevant, both with regard to landowner investment, and the determination of public spending, under a wide range of conditions.

\section{Conclusion}

Since the seminal work by Blume, Rubinfeld, and Shapiro (1984), economists have been concerned with the impact of the compensation rule on land use incentives. Much of the subsequent literature has attempted to provide counterarguments to their famous "no-compensation result" by arguing that, despite the moral hazard problem associated with compensation, there are offsetting economic justifications for the constitutional mandate of "just compensation." The analysis in this paper has shown that this debate may have been unnecessary. In particular, using a constitutional choice framework first developed by Fischel and Shapiro (1989), we have shown that the compensation rule is irrelevant regarding the level of investment landowners make in their property (which will be efficient), and the amount of land they authorize the government to take (which may be efficient, depending on public choice factors).

The intuition for this result is that landowners recognize the equivalence of taxes and takings in budgetary terms, a notion first proposed by Epstein (1985). In particular, they recognize that the expected benefits of a more generous compensation rule will be exactly offset by the resulting increase in expected tax liability. The idea is similar to the macroeconomic concept of Ricardian equivalence. In formal terms, the distortionary 
effects of the compensation rule (moral hazard) and property taxation cancel each other out through the balanced budget condition. This conclusion suggests that consideration of land use incentives, and possibly the level of public good provision (depending on the assumption about government behavior), can be largely ignored in debates about the definition of "just compensation." 


\section{References}

Atkinson, A. and J. Stiglitz (1980), Lectures on Public Economics. New York: McGrawHill.

Blume, L. and D. Rubinfeld (1984), 'Compensation for Takings: An Economic Analysis', California Law Review 72: 569-628.

Blume, L., D. Rubinfeld, and P. Shapiro (1984), 'The Taking of Law: When Should Compensation be Paid?' Quarterly Journal of Economics 99: 71-92.

Cohen, L. (1991), ‘Holdouts and Free Riders', Journal of Legal Studies 20: 351-362.

Epstein, R. (1985), Takings: Private Property and the Power of Eminent Domain. Cambridge, MA: Harvard Univ. Press.

Fischel, W. (1995a), Regulatory Takings: Law, Economics, and Politics. Cambridge, MA: Harvard Univ. Press.

Fischel, W. (1995b), 'The Offer/Ask Disparity and Just Compensation for Takings: A Constitutional Choice Approach'. International Review of Law and Economics $\mathbf{9}$, 115-128.

Fischel, W. and P. Shapiro (1989), 'A Constitutional Choice Model of Compensation for Takings', International Review of Law and Economics 9: 115-128.

Hamilton, B. (1975), 'Zoning and Property Taxes in a System of Local Governments', Urban Studies 12: 205-211.

Hermalin, B. (1995), 'An Economic Analysis of Takings', Journal of Law, Economics, and Organization 11: 64-86.

Kaplow, L. (1986), ‘An Economic Analysis of Legal Transitions', Harvard Law Review 99: 509-617.

Knetsch, J. and T. Borcherding (1979), 'Expropriation of Private Property and the Basis for Compensation', University of Toronto Law Journal 29: 237-252.

Miceli, T. and K. Segerson (1994), 'Regulatory Takings: When Should Compensation Be Paid?’ Journal of Legal Studies 23: 749-776.

Nosal, E. (2001), 'The Taking of Land: Market Value Compensation Should be Paid', Journal of Public Economics 82: 431-443. 